\title{
Basics of research (Part 2): Reviewing the literature
}

Eric Davis

Strong Memorial Hospital

Cheryl Thompson

University of Nebraska Medical Center, cbthompson@unmc.edu

Edward A. Panacek

University of California, Davis

Tell us how you used this information in this short survey.

Follow this and additional works at: https://digitalcommons.unmc.edu/con_articles

Part of the Nursing Commons

\section{Recommended Citation}

Davis, Eric; Thompson, Cheryl; and Panacek, Edward A., "Basics of research (Part 2): Reviewing the literature" (1995). Journal Articles: College of Nursing. 15.

https://digitalcommons.unmc.edu/con_articles/15

This Article is brought to you for free and open access by the College of Nursing at DigitalCommons@UNMC. It has been accepted for inclusion in Journal Articles: College of Nursing by an authorized administrator of DigitalCommons@UNMC. For more information, please contact digitalcommons@unmc.edu. 


\title{
Basics of Research (Part 2): Reviewing the Literature
}

\author{
Eric A. Davis, MD, ${ }^{1}$ Cheryl Bagley Thompson, RN, MSN, PhD, ${ }^{2}$ Edward A. Panacek, MD 3
}

1. Division of Emergency Medicine, University of Pittsburgh, Medical Director, STAT MedEvac, Pittsburgh, Pa.

2. University of Utah, College of Nursing, Salt Lake City, Utah

3. Division of Emergency Medicine and Clinical Toxicology, University of California, Davis, Calif.

Key Words: clinical research, literature review, literature search

Address for correspondence: Eric A. Davis, MD, Center for Emergency Medicine, 230 McKee Place, Suite 500, Pittsburgh, PA 15213
In the first part of the Basics of Research series, you learned how to get started in research and how to formulate an appropriate research question. The next step in the process of developing a research project is to perform a comprehensive review of the literature. The fundamental premise of the research question and subsequent selection of an appropriate study design depends on what gaps cxist in our current understanding. These deficiencies must be assessed accurately to prevent wasting time, energy and resources in addressing a question that has been answered already. Thus, you become an expert on the current state of knowledge for the subject area.

There are multiple ways to obtain a collection of articles in the area of interest. These include references from text chapters, article files from colleagues with knowledge or interest in the subject, references from articles and, finally, the formal literature search. While an author, in all probability, will use all of these methods, no research review is complete without a literature search.

The literature search is an organized method of reviewing scientific information concerning a particular topic. Its focus is on journals. Journals are regarded as the principal vehicle for the communication of information in the medical community and have significant advantages over other information sources, such as texts. Their frequency of publication and shorter preparation time makes them a source for the most recent information, an extremely important point considering the rapidity with which health-care research generates new data. ${ }^{1}$ In addition, journals are the primary channel of communication between medical re- searchers and are the vehicle for the introduction of new ideas, concepts, procedures, etc. ${ }^{2}$ In some journals, articles also are peer reviewed, which means after the paper is submitted individuals with either knowledge or experience concerning the topic of interest critique the study. This serves two basic functions. First, poorly designed, executed or written material is rejected and kept out of print. In actuality this works better as a concept than in practice, but it does mean that the paper must have cleared at least one hurdle prior to publication. Second, the reviewer may make suggestions to the authors to help improve the manuscript, such as clarifying certain sections, reorganizing, adding or deleting data or making other changes designed to improve the project. Thus, for all of these reasons, the journal remains the primary source of background information for any research effort.

Searching the literature is much easier today than it was five to 10 years ago and can be accomplished through a variety of approaches. Previously, finding literature of interest required a slow search through large books such as the Index Medicus or Cumulative Index of Nursing and Allied Health Literature (CINAHL) that indexes health-care related literature by subject heading. If you were looking for research not covered by one of the Medical Subject Headings (MeSH) terms, your chances of finding resources were minimal.

In the past, few individuals had knowledge of proper search techniques. Frequently, the assistance of a librarian was sought. A medical librarian is familiar with health-care terminology and the process for searching through this sub- 


\section{Table 1}

\section{Review Criteria for Evaluation of a New Therapy}

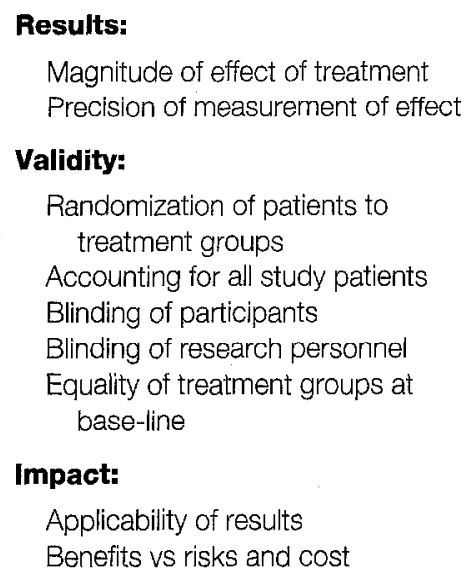

Magnitude of effect of treatment Precision of measurement of effect

Validity:

Randomization of patients to treatment groups Accounting for all study patients Blinding of participants Blinding of research persornel Equality of treatment groups at base-line

Impact:

Applicability of results

Benefits vs risks and cost

set of literature. Medical librarians still can assist you with your search or to conduct the search independently for you. However, in most cases, there is a charge for this service. Consequently, investigators often take advantage of the ease with which the literature now can be searched using computerized tools.

Although Index Medicus is still maintained, it is rarely the first-line reference used, except in small libraries without access to computerized tools. More commonly a variety of computerized resources are used. The first is CD-ROM databases. CD-ROMS are compact disks with read-only memory. They are very similar to the type that contain music, but, in this case, contain large amounts of written material indexed to facilitate retrieval of the desired information.

The two most common databases for searching the health-care literature are MEDLINE and CINAHL. MEDLINE is the National Library of Medicine (NLM) Index of biomedical journal articles. The database covers from 1960 to present in written format (Index Medicus) and from 1966 to present in the CD-ROM version. The database provides references of biomedical literature in English and foreign languages. It also includes all of the nursing journals from the International Nursing Index. ${ }^{3,4}$ MEDLINE is not the only source of biomedical literature but is the most recognized.
Cumulative Index of Nursing and Allied Health Literature concentrates on the nursing and allied health literature and is limited to English language articles. The database includes 1956 to present in print format and 1983 to present in the CD-ROM version. The database references many of the same journals indexed in MEDLINE, but also includes lesser-known nursing and allied health journals and some nonjournal literature, such as doctoral dissertations. In addition, the search terms and data provided are more specific to nursing. ${ }^{4}$ The Air Medical Journal is indexed in CINAHL, but not in MEDLINE.

Most of the research reports and literature needed to conduct a background investigation on your topic will be included in either MEDLINE or CINAHL. However, if you are having difficulty finding material on your topic, a fcw other sources may be worth searching. Hospital Literature Index is a printed reference available via CD-ROM as Health PLAN. Both versions reference health services, facilities, manpower, insurance and regulations from 1981 forward. In addition, Educational Resources Information Center, Health Planning and Administration, ${ }^{\circledR}$ Health and Psychosocial Instruments File, Social Sciences Index and $\mathrm{PsycINFO}^{\circledR}$ reference articles with relevance to health-care providers. These alternative sources may be more helpful if your topic is psychosocial, educational or administrative in nature. Ask the librarian at your hospital or at the nearest college or university for access to these services.

The second source for computerized searching is on-line databases accessed via a computer and modem. On-line searching can be done via direct subscription to the NLM for connecting to MEDLINE, or to a database service, such as Knowledge Index, which has more than 100 databases available for searching. If on-line searching sounds intimidating, try Grateful Med, a software package written specifically for searching MEDLINE via IBM-compatible personal computers and Apple Macintosh ${ }^{\circledR}$ computers. Grateful Med provides an easy-touse interface for searching the database directly and assistance with selecting appropriate search terms for your search.
Once you have developed your search strategy, the software automatically connects to MEDLINE, runs the search requested and allows the retrieval of information while off linc, saving connect-time charges. Alternatively you may subscribe to a general on-line service, such as CompuServe, ${ }^{\circledR}$ America Online ${ }^{\circledR}$ or Prodigy. ${ }^{\circledR}$ On-line services provide a variety of options including access to several databases that can be searched individually.

Costs vary for searching CD-ROMs and on-line databases. Libraries are a common source of CD-ROM databases and may provide free access to authorized users. Some libraries charge for search time or for the number of citations printed. On-line databases charge either by on-line time, number of citations accessed, number of citations printed or any combination of the abovc.

Once you have identified an appropriate database, develop your search strategy. If you have available a list of $\mathrm{MeSH}$ terms, it is best to search through the list to determine what terms are related most closely to your area of interest. Most biomedical databases index by MeSH terms, so your search will be more fruitful if you can use one of the included terms rather than another similar term. Indexes also can be searched by nonMeSH terms, but an article will be retrieved only if the term you request is in the title or abstract.

It will take more than one term to obtain a usable list of references. Most singleterm searches are broad and retrieve more articles than will be useful. A better approach is to use two or three related terms that narrow down your topic. For example, if you are interested in management of neonatal pneumothorax during transport you could use the terms neonatal and pneumothorax. Without the use of both terms you could get all articles on pneumothorax or all on neonates, neither of which would be helpful due to the large number of citations and lack of specificity. The term transport has been deleted from the list of search terms. Just as too few terms yields too many articles, too many terms yields too few articles. If you retrieve too many articles with the first two terms, then you can consider adding a third term (e.g., transport). 
The number of full-text databases is increasing, but, currently, most computerized databases are limited to citation information and a complete abstract. The citation information will help the user to locate a complete copy of the article. The abstract can be used in determining if the article will be of value. Some services, such as Colorado Area Research Libraries, do offer document retrieval services. Colorado Area Research Libraries index more than 14,000 journals and fax a copy of a complete article on request. Charges for the service include copyright fees, fax charges and services charges. If the article can be obtained at a local library or through interlibrary loan, this is a less expensive approach and usually is preferable if time is not a critical element.

Individuals who have performed several literature searches and pored over pilcs of articles relating to a topic have discovered that numerous papers that may impact the project may not be included in the search. It is difficult to explain why this occurs, yet the reviewer must pay attention to the references for each article and pull those that may be relevant. You may want to look at the references used in applicable textbook chapters.

Once you have completed the literature search, a more formidable task awaits-how to decide which articles to retrieve and what information is relevant to the proposed study question. The search, in most cases, generates a large number of articles, and depends on you to reject unsuitable articles to be able to concentrate on those few that may truly impact the project. In most instances, the information necessary to make this selection can be determined from the abstract.

Several points of review should be applied to each article to determine its suitability. First, read the title. It may be obvious that the article is dealing with an area with little or no relevance to the proposed project and may be immediately rejected. Next, review the list of authors. One or more of the authors may be familiar to the searcher, and their track record may be known. If their record is positive and stood the test of time, the article should be considered. The converse is also true--less weight should be given to authors with a less-than-stellar reputa- tion. It may become apparent that an author or group of authors has published a large body of work on a particular subject and may be considered experts in the field. Often, however, most authors will be unfamiliar to you. To a certain extent, consider the reputation of the journal; but this is not foolproof.

Next, read the summary or conclusion. The purpose is to determine whether the results of the paper, if valid, would impact your research question or study design. At this stage, it is not possible to determine if the results are true; the goal is to decide which results, if true, would be useful. Finally, determine if the patient population and the circumstances under which the study took place are relevant to your intended project. The subject of the article should be similar to your intended study population with respect to such variables as agc, scx, discasc, prior treatment, etc. If an article has passed this basic scrutiny, the full article should be retrieved to undergo a detailed review.

After this preliminary screening and a list of working articles has been generated, the next step is to perform an indepth review, paying attention to the methods section. The review procedure varies depending on the type of article in question, and an excellent discussion is available in a recent series of articles published in the Journal of the American Medical Association. 2,5-11 While a brief review is presented here, the scope of this undertaking is beyond what can be covered in a single paper. A complete reading of the original series is highly recommended.

The process of review for each type of article may be divided into three basic questions:

1. What are the actual results?

2. Are the results of the study valid?

3. Will the results of the study impact clinical care and/or project design?

The process used to determine the validity of the paper varies with the design or intent of the study. Medical articles can be placed into one of the following categories:

1. Evaluation of a new therapy

2. Evaluation of a new diagnostic test

3. Determination of the etiology of a condition

\section{Table 2}

Review Criteria for Evaluation of a New Test

\section{Results:}

Presentation of likelihood ratios

\section{Validity:}

Blind and independent comparison to an accepted gold standard

Application of test to wide patient spectrum

Effect on performance of gold standard

Ease of test replication

\section{Impact:}

Patient applicability Effect of patient management Effect on patient care

\section{Prediction of the outcome or} natural course of a condition

Each of these categories has differing criteria for scientific value. These criteria are listed in Tables 1, 2,3 and 4 .

Articles dealing with evaluation of a new therapy should be approached in the following manner. With respect to results, the magnitude of the treatment effect should be explored. The larger the difference between individuals receiving therapy and individuals who have not, the more clinically significant the treatment is likely to be. The accuracy of the measurement of effect is also important-the more precise and reliable the measurement, the greater the confidence in the results. Accuracy is influenced by the quality of your measurement results, instrument and the appropriateness of your measure. Precision is affected by the number of trial participants; larger studies give a more focused estimate of effect. Validity, defined as whether the measured effect represents the true direction and magnitude of the treatment effect, is affected by a number of conditions. The participants should be randomized properly to the treatment and control groups, and the process must not be influenced by outside factors. All patients entered into the study should be accounted for at the end; if a large number are lost, the reported findings may not be valid. Both the subjects and those administering treatment should be blinded to what therapy is being used on 


\section{Table 3}

Review Criteria for Etiology of Condition

Results:

Strength of exposure to outcome

Precise risk estimato

\section{Validity:}

Group similarity other than point of interest

Same exposure measurements

Strong temporal relationship

Adequate follow-up

\section{Impact:}

Results apply to patient population Magnitude of risk

\section{Table 4}

\section{Review Criteria for Prediction of Outcome}

\section{Results:}

Magnitude of outcome likelihood

Precision of likelihood estimate

\section{Validity:}

Representative patient sample

Sufficient follow-up

Use of unbiased and objective

outcome criteria

\section{Impact:}

Equivalent patient population for comparison

Effect on therapy choice

each individual ("double-blind study"), if possible. This prevents any conscious or unconscious manipulation of the results by the participants. Treatment and control groups should be equal in all aspects except the experimental therapy to prevent any confounding effect on outcome. Finally, the relevance to your experience and clinical care must be evaluated. How well do the study patients reflect your own patients? The benefit of therapy must be weighed against potential risks and any increased costs. Sometimes a value judgment must be applied.

Studies involving the evaluation of a new test should be evaluated for likelihood ratios, or how well the test predicts the presence or absence of a condition in an individual patient. Obviously, the higher the probability that a positive test is associated with the disease state and that a negative test occurs in the patient without the condition, the more valuable the test. The test should be evaluated by a blind and independent comparison to an accepted "gold standard," ideally the diagnostic test in most common use for the suspected disorder. The trial should apply the test to a wide variety of patients, covering the entire clinical spectrum that the caregiver is likely to encounter. The potential effect on the performance of the current gold standard should be addressed. If the new test adds little to the current method of evaluation or is not less expensive or more time efficient, it is unlikely to have a substantial clinical impact. The new test must be able to be replicated easily by those planning on using it. The applicability to your patient care should be evaluated, by comparing the study patients to your own patients. Would the performance of the test have any affect on patient management? Will the test result in changing a therapy and will the patients be better off as a result?

Prediction of the etiology of a condition is concerned with the issue of cause and effect. The results should be viewed with respect to the strength of exposure that results in a particular outcome, i.e., how often the exposure results in the patient being affected by the outcome of interest. As previously discussed, the precision of the risk estimate should be evaluated. Validity was increased if the groups being studied were as similar as possible in all respects affecting outcome except the risk factor being studied. Commonly this is reported in the results section as the "base-line" parameters or demographics and deals with such factors as age, gender, race, etc. Proper randomization procedures are preferred to limit possible sources of bias, and the groups being compared must have their exposures and outcomes measured by the same method. Randomization of exposures (e.g., motor-vehicle accident, cocaine use) cannot be achieved always.

The authors should demonstrate that the proper temporal sequence exists. The exposure must precede the outcome, and the strength of the association is enhanced by a dose-response relationship. This means that as the magnitude or duration of the exposure increases, so does the occurrence of the outcome in question. The patients must be followed up for an appropriate period of time to ensure capture of all relevant events. An exposure that results in an outcome decades after the fact is obviously not addressed by a five-year follow-up period. Once again, compare the study and your clinical population to determine whether the results can be extrapolated to your situation. The clinical importance, or magnitude of the risk, should be addressed to determine if manipulation of the environment is warranted to prevent the undesirable outcome.

The fourth grouping of articles, those concerned with prediction of outcome, use many similar review points as the previous sections. The results are evaluated by the magnitude of outcome likelihood, or how large the occurrence of events is within a specified period of time. Precision must be addressed. Validity is judged by determining if a patient sample is truly representative of the entire population in question, and if sufficient follow-up occurred. The crileria for judging the outcome criteria must be unbiased and objective to prevent the researchers from influencing the true result. Similarity of the study patients to your own should be considered. Most important is the determination of whether the results of the study lead to changes in therapy or other practices.

Several general points apply to every review process. Good papers will discuss their own limitations, ustrally in one of the last few paragraphs prior to the conclusion. Pay attention to this discussion, as small problems may have a large effect on the research results. One must realize that statistical significance does not equate to clinical significance. Statistical significance addresses only the possibility that the results could have occurred by chance alone, and, as such, is dependent on factors such as sample size. Statistical significance tells you absolutely nothing about the actual magnitude of the clinical differences between groups. These and other related issues will be discussed in greater detail in a future segment of this series specifically focusing on statistics.

While this process seems tedious and laborious (and, at times, it is) it is necessary. Many of the same papers will be 
used later to support a research proposal, grant application or manuscript preparation. As such, it is useful to take notes as you read the articles, highlighting significant points and major flaws. One helpful method is to number the articles, keeping ordered notes concerning each pa- per. After completion, summarize your findings, which is especially helpful if you are to prepare a research-in-progress report.

Finally, after all this careful, critical review, you can determine if enough satisfactory work on the topic has been done to adequately answer the research question. You are an expert on the subject at hand and have a clear picture of how to begin formulating the actual project. The next step is to develop the research question and select an appropriate research design.

\section{References}

1. Hawkins and Sorgi: Research How to Plan, Speak and Write About It. Berlin, Springer-Verlag, 1985.

2. Oxman AD, Sackett DL, Guyatt GH: Users guides to the medical literature I: How to get started. JAMA 1993;270:2093-2096.

3. Cassey MZ, Kane WP, Sutton LS: On-line access to nursing literature. Comp Nurs 1993; 11:230-235.

4. Kilby SA, McAlindon MN: Searching the literature yourself: Why, how, and what to search. In: Computer Applications in Nursing Education and Practice. Arnold JM, Pearson GA (eds): New York, National League for Nursing, 1992.

5. Guyett GH, Sackett DL, Cook DJ: Users guides to the medical literature II; How to use an article about therapy or prevention $A$. Are the results of the study valid? JAMA 1993; 270:2598-2601.

6. Guyatt GH, Sackett DL, Cook DJ: Users guides to the medical literature II: How to use an article about therapy or prevention $\mathrm{B}$ ? What were the results and will they help me in caring for my patients? JAMA 1994;271:59-63.

7. Jacschke R, Guyatt G, Sackett DL: Users guides to the medical literature III: How to use an article about a diagnostic test A: Are the results of the study valid? JAMA 1994:271:389-391.

8. Jaeschke R, Guyatt GH, Sackett DL: Users guides to the medical literature III: How to use an article about a diagnostic test B. What are the results and will they help me in caring for my patients? IAMA 1994:271:703-707.

9. Levine $M$, Walters, Lee $H$, et al: Users guides to the medical literature IV: How to use an article about harm. JAMA 1994; 271:1615-1619.

10. Iaupacis A, Wells $G$, Richardson $S$, et al: Users guides to the medical litcrature V: How to use an. article about prognosis. JAMA 1994;272:234-237.

11. Oxman AD, Cook DS, Guyatt GH: Users guides to the medical literature VI: How to use an overview. JAMA 1994;272:1367-1371. 